\title{
OBSTACLES IN THE MANAGEMENT OF OBSTETRIC AND NEONATAL EMERGENCY SERVICES IN DEVELOPING COUNTRIES: A SYSTEMATIC REVIEW
}

\author{
Liberata Jayanti, Sulistyaningsih \\ Universitas Aisyiyah Yogyakarta
}

\begin{abstract}
Background: Provision of obstetric and neonatal emergency services is an effective ways to reduce maternal and infant morbidity and mortality. Currently, the achievement obstetric and neonatal emergency services in Indonesia is $25 \%$, services preparedness is $86 \%$, hospital capacity in blood transfusion service is $55 \%$, and blood supply sufficiency is $41 \%$. Effective obstetric and neonatal emergency services require proper management of drug, equipment, infrastructure, and trained staff. The staff should demonstrate competency in diagnosing and managing complication. This study aimed to systematically review the obstacles in the management of obstetric and neonatal emergency services in developing countries.

Subjects and Method: A systematic review was conducted with data sources obtained from PubMed, ProQuest, and One Search. The inclusion criteria were health workers in community health center (Puskesmas) and hospital, full free text, articles from 2014 to 2018, and international journals. The studies were appraised using the Critical Appraisal Skills Program (CASP) and the synthesized using PEOS modification.

Results: There were four types of obstacles: (1) Low quality human resources; (2) Lack of care and skills; (3) Transportation and referral; and (4) Lack of infrastructure. The management of obstetric and neonatal emergencies in midwifery services can be improved by upgrading human resources through skill training and by improving transportation and infrastructure.

Conclusion: Four types of obstacles in obstetric and neonatal emergency services have been identified, including the quality and skill of human resources, lack of transportation and infrastructure. The management of obstetric and neonatal emergencies in midwifery services can be improved by upgrading human resources through skill training and by improving transportation and infrastructure.
\end{abstract}

Keywords: obstacle, obstetric, neonatal, emergency, management

\section{Correspondence:}

Liberata Jayanti. Universitas Aisyiyah Yogyakarta. Jl. Siliwangi (Ring Road West) No. 63 Mlangi, Nogotirto, Gamping, Sleman, Yogyakarta, 55292. Email: ljyhantie.2901@gmail.com. Mobile: 085245028220 . 